\title{
Tamanho de amostra para a estimação da média de caracteres de maçã
}

\author{
Sample size for estimate the average of characters in apples
}

\author{
Marcos Toebe ${ }^{\mathrm{I}}$ Vanderlei Both ${ }^{\mathrm{I}}$ Fabio Rodrigo Thewes ${ }^{\mathrm{II}}$ Alberto Cargnelutti Filho ${ }^{\mathrm{II}}{ }^{*}$ \\ Auri Brackmann ${ }^{\text {III }}$
}

RESUMO

O objetivo deste trabalho foi determinar o tamanho de amostra (número de frutos) necessário para a estimação da média de caracteres de maçãs Royal Gala e Fuji, avaliados na colheita e pós-colheita, após período sob armazenamento refrigerado. Em frutos de macieira Royal Gala e Fuji, foram mensurados oito caracteres na colheita e 11 caracteres após armazenamento refrigerado. Para cada caractere mensurado em cada cultivar, na colheita e após o armazenamento refrigerado, foram calculados a média, a variância, o coeficiente de variação, a assimetria, a curtose e verificada a normalidade e, em seguida, calculado o tamanho de amostra. Maior tamanho de amostra é necessário para a estimação da média de: produção de etileno, ratio, respiração, massa e acidez titulável. Menor tamanho de amostra é necessário para a mensuração de: diâmetro longitudinal, firmeza de polpa, sólidos solúveis totais, diâmetros transversais (maior e menor) e teor de suco. O tamanho de amostra necessário para a mensuração de caracteres de maçãs Royal Gala é menor em relação ao necessário para maçãs Fuji. Em maçãs Royal Gala e Fuji, 88 e 190 frutos, respectivamente, são suficientes para a mensuração de caracteres na colheita e após o armazenamento refrigerado, com erro de estimação de $5 \%$ da média.

Palavras-chave: Malus domestica, amostragem, planejamento experimental, pós-colheita.

\section{ABSTRACT}

The aim of this research was to determine the sample size (number of fruits) needed to estimate the average of Royal Gala and Fuji apples characters, evaluated at harvest and postharvest, after a period in cold storage. In Royal Gala and Fuji apples were measured eight characters at harvest and 11 after could refrigeration. For each character in each cultivar, measured at harvest and after cold storage, was calculated the mean, variance, coefficient of variation, skewness, kurtosis and checked the normality and, then, was calculated the sample size. Larger sample sizes are needed to estimate the average of: ethylene production, ratio, respiration, weight and acidity. Smaller sample sizes are needed for the measurement of longitudinal diameter, pulp firmness, total soluble solids, transversal diameters (major and minor) and juice content. The sample size required to measure the characters of Royal Gala apples is lower than that required for Fuji apples. In Royal Gala and Fuji apples, 88 and 190 fruits, respectively, are sufficient for the measurement of characters, at harvest and after cold storage, with estimation error of $5 \%$ of the average.

Key words: Malus domestica, sampling, experimental design, post-harvest.

\section{INTRODUÇÃO}

Os estados do Rio Grande do Sul e de Santa Catarina são os principais produtores de macieira (Malus domestica) do Brasil, com produção anual de 1,1 milhões de toneladas de frutos de maçãs (AGRIANUAL, 2010), sendo que as cultivares 'Gala' e 'Fuji' e suas mutantes são as mais produzidas. As mutantes da cultivar 'Gala', como, por exemplo, a 'Royal Gala', apresentam epiderme vermelha rajada, lisa e brilhante, polpa firme, crocante, suculenta e uma adequada relação entre ácidos e sólidos solúveis (BRACKMANN et al., 2008). Já a maçã Fuji apresenta ampla aceitação do mercado consumidor, em função do excelente sabor e polpa crocante e suculenta (BRACKMANN et al., 2009). Tendo em vista o curto período de colheita,

\footnotetext{
IPrograma de Pós-graduação em Agronomia, Universidade Federal de Santa Maria (UFSM), Santa Maria, RS, Brasil.

${ }^{\text {IIC }}$ rsso de Agronomia, UFSM, Santa Maria, RS, Brasil.

III Departamento de Fitotecnia, Centro de Ciências Rurais (CCR), UFSM, 97105-900, Santa Maria, RS, Brasil. E-mail: alberto.cargnelutti.filho@gmail.com.*Autor para correspondência. 
com início em fevereiro para as mutantes da Gala e término em abril, com a colheita da Fuji, é necessário o armazenamento dessas maçãs, a fim de prolongar a sua oferta ao mercado consumidor.

Uma das técnicas que pode ser utilizada no armazenamento de maçãs é o armazenamento refrigerado, com controle da temperatura e umidade relativa (UR) do ambiente de armazenagem. O controle da temperatura contribui para manutenção da qualidade pós-colheita de frutos, pois reduz a velocidade das reações bioquímicas, retardando o amadurecimento dos frutos (CHITARRA \& CHITARRA, 2005). O controle da UR no armazenamento é importante, pois, em baixa UR, ocorre perda de massa e murchamento dos frutos, além do aumento da produção de etileno, acelerando a senescência dos frutos (NAKANO et al., 2003) e, em elevada UR, pode ocorrer proliferação de patógenos (SCHWARZ, 1994). Assim, a indução da perda de massa até certo limite pode ser benéfica para manutenção da qualidade pós-colheita de maçãs (BRACKMANN et al., 2007).

É importante avaliar corretamente características morfológicas e de qualidade de frutos para a determinação do ponto de colheita de uma cultura. Ainda, durante o armazenamento dos frutos colhidos e após, quando são transportados e comercializados, ocorrem alterações morfológicas, bioquímicas e físicas que estão relacionadas com a qualidade (CHITARRA \& CHITARRA, 2005). Portanto, em pesquisas com a cultura de maçã, é necessário determinar corretamente as principais características dos frutos na colheita e após o armazenamento, quando eles serão consumidos.

O tamanho de amostra (número de frutos) depende da variabilidade dos dados, da confiabilidade desejada e do erro de estimação permitido (BUSSAB \& MORETTIN, 2004; SPIEGEL et al., 2004). Esses fatores foram considerados em estudos do tamanho de amostra para a mensuração de caracteres morfológicos de pimenteira (SILVA et al., 2011), do padrão de crescimento e diâmetro dos frutos de laranja Valencia late (AVANZA et al., 2010), do diâmetro e peso médio de frutos de maçã Ariane e Pitchounette (MIRANDA et al., 2007) e do teor de suco, sólidos solúveis totais, acidez e ratio em laranja Valencia (BARRY et al., 1999). Para a mensuração de características físicas e químicas de frutos de maracujá-amarelo (COELHO et al., 2011), da firmeza de polpa e cor de fundo de epiderme de pêssego Eragil e maçã Royal Gala (TOEBE et al., 2011) e para a estimação da média de caracteres de pêssego Eldorado (TOEBE et al., 2012), foram estabelecidos tamanhos de amostra para a mensuração desses caracteres no momento da colheita e após o armazenamento dos frutos.

O objetivo deste trabalho foi determinar o número de frutos necessário para a estimação da média de caracteres de maçãs Royal Gala e Fuji avaliados na colheita e pós-colheita, após período sob armazenamento refrigerado.

\section{MATERIAL E MÉTODOS}

As maçãs das cultivares 'Royal Gala' e 'Fuji' foram colhidas, respectivamente, nos dias 20/02/2011 e 25/04/2011, em um pomar comercial do município de Vacaria, Estado do Rio Grande do Sul. Logo após a colheita, os frutos foram transportados até o Núcleo de Pesquisa em Pós-colheita (NPP) do Departamento de Fitotecnia da Universidade Federal de Santa Maria (UFSM), no município de Santa Maria, Estado do Rio Grande do Sul. No NPP, foi realizada a eliminação de frutos com defeitos ou danos mecânicos.

Em seguida, 120 frutos de macieira Royal Gala foram utilizados para a mensuração dos caracteres no momento da colheita (amostra 1) e outros 120 frutos foram armazenados dentro de minicâmaras em ambiente refrigerado, durante três meses, na temperatura de $0,5^{\circ} \mathrm{C}$ (amostra 2), totalizando 240 frutos de macieira Royal Gala. Em macieira Fuji, foram usados 120 frutos para a mensuração de caracteres no momento da colheita (amostra 3) e 111 frutos foram armazenados dentro de minicâmaras em ambiente refrigerado, durante quatro meses a $-0,5^{\circ} \mathrm{C}$ (amostra 4), totalizando 231 frutos de macieira Fuji. Nas duas cultivares, a umidade relativa durante o armazenamento foi de $96 \%( \pm 1 \%)$. Após o armazenamento refrigerado (para as amostras 2 e 4 ), as maçãs foram expostas à temperatura de $20^{\circ} \mathrm{C}$ durante cinco dias, a fim de simular o período de prateleira.

Os caracteres mensurados em cada um dos 120 frutos de macieira Royal Gala e 120 frutos de macieira Fuji na colheita foram: massa, determinada com o uso de balança digital com precisão de $0,001 \mathrm{~g}$; diâmetros longitudinal e transversais (maior e menor), determinados com o uso de paquímetro com precisão de $1 \mathrm{~mm}$; firmeza de polpa, determinada com o uso de penetrômetro com ponteira de $11,0 \mathrm{~mm}$, inserido em lados opostos da região equatorial do fruto, de onde previamente havia sido retirada a epiderme; sólidos solúveis totais ( $\mathrm{SST}$, em ${ }^{\circ}$ Brix), determinados com uso de refratômetro com correção da temperatura; acidez titulável (em \% de ácido málico), determinada pela titulação de uma solução de $10 \mathrm{~mL}$ de suco diluído em $100 \mathrm{~mL}$ de água, com $\mathrm{NaOH} 0,1 \mathrm{~N}$; e ratio, obtido pela razão entre SST e acidez titulável. 
Em cada um dos 120 frutos de macieira Royal Gala e 111 frutos de macieira Fuji submetidos ao armazenamento refrigerado, seguido de cinco dias a $20^{\circ} \mathrm{C}$, foram mensurados os caracteres massa, diâmetros longitudinal e transversais (maior e menor), firmeza de polpa, SST, acidez titulável, ratio, teor de suco, produção de etileno e respiração. $\mathrm{O}$ teor de suco foi determinado pela prensagem de, aproximadamente, $20 \mathrm{~g}$ de polpa de cada fruto. A polpa foi colocada entre duas tiras de esponjas, com dimensões de $13 \times 13 \times 3 \mathrm{~cm}$, que, em seguida, foi pressionada durante 30 segundos por um pistão pneumático contra uma massa de $1.500 \mathrm{~kg}$, sendo as amostras pesadas antes e após a prensagem e, por diferença, se obteve o teor de suco (\%). A produção de etileno foi determinada pelo acondicionamento de cada fruto em um frasco com volume de $800 \mathrm{~mL}$, com fechamento hermético, de onde foram retiradas duas alíquotas de $1 \mathrm{~mL}$ e injetadas em um cromatógrafo a gás da marca Varian ${ }^{\circledR}$ equipado com coluna Porabak N e detector de ionização por chama, com temperatura da coluna, do injetor e do detector de $90,140,200^{\circ} \mathrm{C}$, respectivamente, sendo os dados expressos em $\mu \mathrm{LC}_{2} \mathrm{H}_{4}$ $\mathrm{kg}^{-1} \mathrm{~h}^{-1}$. A respiração foi determinada pela circulação do ar contido no mesmo recipiente da produção de etileno, por analisador de gases da marca Agridatalog ${ }^{\circledR}$, expressando os dados em $\mathrm{mL} \mathrm{CO}_{2} \mathrm{~kg}^{-1} \mathrm{~h}^{-1}$.

Para cada caractere mensurado em cada cultivar, tanto na colheita como após o armazenamento refrigerado, foi calculada a média, a variância, o coeficiente de variação, a assimetria, a curtose e o valor-p do teste de normalidade de Kolmogorov-Smirnov. A seguir, para cada caractere mensurado, aplicaram-se os testes $\mathrm{t}$ (bilateral) e F (bilateral), a 5\% de probabilidade de erro, para testar, respectivamente, as hipóteses de igualdade das médias e de homogeneidade das variâncias. $\mathrm{Na}$ aplicação desses testes, foram consideradas as seguintes amostras independentes: amostra $1=120$ frutos da cultivar 'Royal Gala' avaliados na colheita; amostra $2=120$ frutos da cultivar 'Royal Gala' avaliados após o armazenamento refrigerado; amostra $3=120$ frutos da cultivar 'Fuji' avaliados na colheita; amostra $4=111$ frutos da cultivar 'Fuji' avaliados após o armazenamento refrigerado. Assim, os testes $\mathrm{t}$ (bilateral) e F (bilateral) foram aplicados para as seguintes comparações: amostra 1 versus amostra 2; amostra 1 versus amostra 3; amostra 1 versus amostra 4; amostra 2 versus amostra 3; amostra 2 versus amostra 4; amostra 3 versus amostra 4 . Os resultados dessas comparações foram representados por letras ao lado das médias e das variâncias, respectivamente, para os testes t (bilateral) e F (bilateral). O valor do teste F (bilateral) foi calculado pela razão entre a amostra com maior variância e amostra com menor variância ( $\mathrm{F}=$ maior variância/menor variância), com n-1 graus de liberdade no numerador e m-1 graus de liberdade no denominador. O resultado do teste F, ou seja, a conclusão se as amostras apresentaram variâncias heterogêneas ou variâncias não heterogêneas, foi considerado na comparação das médias de amostras independentes por meio do teste $\mathrm{t}$ (bilateral) (BUSSAB \& MORETTIN, 2004).

Para cada caractere, em cada cultivar e momento de avaliação, ou seja, para cada uma das quatro amostras independentes, calculou-se o tamanho de amostra (ç) para as semiamplitudes do intervalo de confiança (erros de estimação) iguais a $1,2, \ldots, 10 \%$ da estimativa da média $(\mathrm{m})$, com grau de confiança $(1-\alpha)$ de $95 \%$. Para isso, usou-se a expressão $\eta=\left(\mathrm{t}_{\alpha / 2}^{2} \mathrm{~s}^{2}\right) /(\text { erro de estimação })^{2}$ (BUSSAB \& MORETTIN, 2004; SPIEGEL et al., 2004), sendo $t_{\alpha / 2}$ o valor crítico da distribuição $t$ de Student, cuja área à direita é igual a $\alpha / 2$, com (n-1) graus de liberdade, $\alpha=5 \%$ de probabilidade de erro e $s^{2}$ a estimativa da variância. A seguir, fixou-se $\eta$ em 120 frutos para maçãs Royal Gala avaliadas na colheita (amostra 1) e após o armazenamento refrigerado (amostra 2) e para maçãs 'Fuji' avaliadas na colheita (amostra 3) e $\eta$ em 111 frutos para maçãs 'Fuji' avaliadas após o armazenamento refrigerado (amostra 4). Após, foi calculado o erro de estimação em percentagem da estimativa da média $(\mathrm{m})$ para cada caractere, por meio da expressão:

erro de estimação $=\left(100 \mathrm{t}_{\alpha / 2} \mathrm{~s}\right) /(\sqrt{\eta} \mathrm{m})$, em que $\mathrm{s}$ é a estimativa do desvio padrão. As análises estatísticas foram realizadas com auxílio do programa GENES (CRUZ, 2006) e do aplicativo Microsoft Office Excel ${ }^{\circledR}$.

\section{RESULTADOS E DISCUSSÃO}

Em média, as maçãs Royal Gala apresentaram massa e diâmetros transversais (maior e menor) inferiores em relação às maçãs 'Fuji', tanto na colheita como após o armazenamento refrigerado (Tabela 1). Por outro lado, o diâmetro longitudinal dos frutos foi superior nas maçãs Royal Gala em relação às maçãs Fuji. No momento da colheita, os frutos da cultivar 'Royal Gala' apresentavam maior firmeza de polpa em relação aos frutos da cultivar 'Fuji', sendo que, após o armazenamento refrigerado, houve redução da firmeza para ambas as cultivares em função do amadurecimento, sem diferenças significativas entre cultivares $(\mathrm{P}>0,05)$.

$\mathrm{Na}$ colheita e após o armazenamento refrigerado, as maçãs Royal Gala apresentaram menor 
Tabela 1 - Média, variância e coeficiente de variação de caracteres mensurados em quatro amostras, ou seja, na colheita (COL) e após o armazenamento refrigerado (AAR) em frutos de maçãs 'Royal Gala' e 'Fuji'.

\begin{tabular}{|c|c|c|c|c|c|}
\hline \multirow[b]{2}{*}{ Caractere } & \multirow[b]{2}{*}{ Unidade } & \multicolumn{2}{|c|}{------------ 'Royal Gala' -------------- } & \multicolumn{2}{|c|}{--------------- 'Fuji' --------------' } \\
\hline & & $\begin{array}{c}\operatorname{COL}(n=120) \\
\operatorname{amostra} 1\end{array}$ & $\begin{array}{l}\text { AAR }(n=120) \\
\text { amostra } 2\end{array}$ & $\begin{array}{c}\mathrm{COL}(\mathrm{n}=120) \\
\operatorname{amostra} 3\end{array}$ & $\begin{array}{c}\text { AAR }(n=111) \\
\operatorname{amostra} 4\end{array}$ \\
\hline & & \multicolumn{4}{|c|}{ 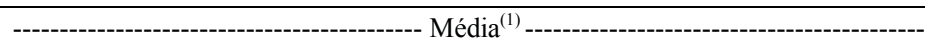 } \\
\hline Massa & $\mathrm{g}$ & $155,55 \mathrm{~b}$ & $147,52 \mathrm{c}$ & $167,74 \mathrm{a}$ & $167,26 \mathrm{a}$ \\
\hline Diâmetro longitudinal & $\mathrm{mm}$ & $65,53 \mathrm{a}$ & $64,43 \mathrm{ab}$ & $62,58 \mathrm{c}$ & $62,99 \mathrm{bc}$ \\
\hline Diâmetro transversal maior & $\mathrm{mm}$ & $70,98 \mathrm{~b}$ & $69,67 \mathrm{c}$ & $74,28 \mathrm{a}$ & 74,44 a \\
\hline Diâmetro transversal menor & $\mathrm{mm}$ & $68,13 \mathrm{~b}$ & $66,65 \mathrm{c}$ & $69,85 \mathrm{a}$ & $70,23 \mathrm{a}$ \\
\hline Firmeza de polpa & $\mathrm{N}$ & $76,21 \mathrm{a}$ & $60,61 \mathrm{c}$ & $68,85 \mathrm{~b}$ & $60,13 \mathrm{c}$ \\
\hline Sólidos solúveis totais & ${ }^{\circ}$ Brix & $11,43 \mathrm{c}$ & $12,33 \mathrm{~b}$ & $12,68 \mathrm{a}$ & $12,48 \mathrm{ab}$ \\
\hline Acidez titulável & \% ác. málico & $0,31 \mathrm{a}$ & $0,22 \mathrm{c}$ & $0,23 \mathrm{~b}$ & $0,12 \mathrm{~d}$ \\
\hline Ratio & ${ }^{\circ} \mathrm{Brix} / \%$ ác. málico & $37,12 \mathrm{~d}$ & $57,43 \mathrm{~b}$ & $54,80 \mathrm{c}$ & $111,52 \mathrm{a}$ \\
\hline Teor de suco & $\%$ & - & $71,56 \mathrm{~b}$ & - & $75,97 \mathrm{a}$ \\
\hline Etileno & $\mu \mathrm{L} \mathrm{C} \mathrm{C}_{2} \mathrm{H}_{4} \mathrm{~kg}^{-1} \mathrm{~h}^{-1}$ & - & $128,27 \mathrm{a}$ & - & $38,76 \mathrm{~b}$ \\
\hline Respiração & $\mathrm{mL} \mathrm{CO}_{2} \mathrm{~kg}^{-1} \mathrm{~h}^{-1}$ & - & 15,73 a & - & $11,94 \mathrm{~b}$ \\
\hline & & - n n n n & ----------Variấ & 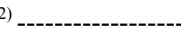 & \\
\hline Massa & $\mathrm{g}$ & $740,43 \mathrm{~b}$ & $569,19 \mathrm{~b}$ & $1.836,04 \mathrm{a}$ & $1.567,89 \mathrm{a}$ \\
\hline Diâmetro longitudinal & $\mathrm{mm}$ & $28,64 \mathrm{bc}$ & $24,53 \mathrm{c}$ & $46,06 \mathrm{a}$ & $40,25 \mathrm{ab}$ \\
\hline Diâmetro transversal maior & $\mathrm{mm}$ & $20,61 \mathrm{~b}$ & $15,67 \mathrm{~b}$ & $45,08 \mathrm{a}$ & $37,58 \mathrm{a}$ \\
\hline Diâmetro transversal menor & $\mathrm{mm}$ & $16,23 \mathrm{~b}$ & $13,39 \mathrm{~b}$ & $32,20 \mathrm{a}$ & 30,22 a \\
\hline Firmeza de polpa & $\mathrm{N}$ & $38,93 \mathrm{a}$ & $27,27 \mathrm{a}$ & $37,65 \mathrm{a}$ & $30,80 \mathrm{a}$ \\
\hline Sólidos solúveis totais & ${ }^{\circ}$ Brix & $0,45 \mathrm{~b}$ & $0,47 \mathrm{~b}$ & $1,82 \mathrm{a}$ & $1,81 \mathrm{a}$ \\
\hline Acidez titulável & \% ác. málico & $0,0011 \mathrm{a}$ & $0,0010 \mathrm{a}$ & $0,0010 \mathrm{a}$ & $0,0008 \mathrm{a}$ \\
\hline Ratio & ${ }^{\circ} \mathrm{Brix} / \%$ ác. málico & $18,64 \mathrm{c}$ & $72,72 b$ & $60,73 \mathrm{~b}$ & $1.009,01 \mathrm{a}$ \\
\hline Teor de suco & $\%$ & - & $8,12 \mathrm{a}$ & - & $6,71 \mathrm{a}$ \\
\hline Etileno & $\mu \mathrm{L} \mathrm{C}_{2} \mathrm{H}_{4} \mathrm{~kg}^{-1} \mathrm{~h}^{-1}$ & - & $920,67 \mathrm{a}$ & - & $181,24 \mathrm{~b}$ \\
\hline \multirow[t]{2}{*}{ Respiração } & $\mathrm{mL} \mathrm{CO} \mathrm{kg}^{-1} \mathrm{~h}^{-1}$ & - & $5,42 \mathrm{~b}$ & - & $9,95 \mathrm{a}$ \\
\hline & & \multicolumn{4}{|c|}{  } \\
\hline Massa & $\mathrm{g}$ & 17,49 & 16,17 & 25,54 & 23,67 \\
\hline Diâmetro longitudinal & $\mathrm{mm}$ & 8,17 & 7,69 & 10,85 & 10,07 \\
\hline Diâmetro transversal maior & $\mathrm{mm}$ & 6,40 & 5,68 & 9,04 & 8,23 \\
\hline Diâmetro transversal menor & $\mathrm{mm}$ & 5,91 & 5,49 & 8,12 & 7,83 \\
\hline Firmeza de polpa & $\mathrm{N}$ & 8,19 & 8,62 & 8,91 & 9,23 \\
\hline Sólidos solúveis totais & ${ }^{\circ}$ Brix & 5,89 & 5,57 & 10,64 & 10,78 \\
\hline Acidez titulável & \% ác. málico & 10,55 & 14,19 & 13,57 & 24,41 \\
\hline Ratio & ${ }^{\circ} \mathrm{Brix} / \%$ ác. málico & 11,63 & 14,85 & 14,22 & 28,48 \\
\hline Teor de suco & $\%$ & - & 3,98 & - & 3,41 \\
\hline Etileno & $\mu \mathrm{L} \mathrm{C}_{2} \mathrm{H}_{4} \mathrm{~kg}^{-1} \mathrm{~h}^{-1}$ & - & 23,66 & - & 34,74 \\
\hline Respiração & $\mathrm{mL} \mathrm{CO}_{2} \mathrm{~kg}^{-1} \mathrm{~h}^{-1}$ & - & 14,80 & - & 26,42 \\
\hline
\end{tabular}

(1) As médias dos caracteres não seguidas pela mesma letra na linha, diferem pelo teste t bilateral, a 5\% de probabilidade de erro. ${ }^{(2)}$ As variâncias dos caracteres não seguidas pela mesma letra na linha, são heterogêneas pelo teste $\mathrm{F}$ bilateral, a $5 \%$ de probabilidade de erro. Os testes t (bilateral) e F (bilateral) foram aplicados para as seguintes comparações: amostra 1 versus amostra 2; amostra 1 versus amostra 3; amostra 1 versus amostra 4; amostra 2 versus amostra 3; amostra 2 versus amostra 4; amostra 3 versus amostra 4.

teor de sólidos solúveis totais (SST) e maior acidez titulável, resultando em menor ratio em relação às maçãs Fuji (Tabela 1). Ainda, após o armazenamento refrigerado, o teor de sólidos solúveis totais aumentou nas maçãs Royal Gala e não houve alterações significativas em maçãs Fuji. Já a acidez titulável reduziu nas duas cultivares após o armazenamento refrigerado e, consequentemente, o ratio foi superior após o armazenamento. Durante o amadurecimento de maçãs, geralmente ocorre inicialmente um aumento do teor de SST em função da degradação do amido presente nos frutos. Num estado mais avançado de maturação, os SST (em sua grande maioria açúcares) são consumidos pelo processo respiratório, sendo 
que o início de sua utilização se dá após o consumo de ácidos orgânicos (BRACKMANN \& SAQUET, 1995). Entre as cultivares, a 'Royal Gala' apresentou menor teor de suco e maior produção de etileno e respiração, indicando maior atividade metabólica.

Os caracteres firmeza de polpa e acidez titulável apresentaram variâncias homogêneas $(\mathrm{P}>0,05)$ entre frutos Royal Gala e Fuji avaliadas tanto na colheita como após o armazenamento refrigerado (Tabela 1). O teor de suco, avaliado apenas após o armazenamento, também apresentou variâncias homogêneas para frutos Royal Gala e Fuji, sugerindo a utilização de um tamanho de amostra único para essas duas cultivares. Porém, as médias desses caracteres (firmeza de polpa, acidez titulável e teor de suco) diferem entre cultivares e momentos de avaliação. Assim, mesmo que para esses caracteres tenha sido verificada homogeneidade de variâncias entre cultivares e momentos da avaliação, podese ter tamanhos de amostra diferentes, pois o erro de estimação (denominador da expressão para o cálculo do tamanho de amostra) foi estabelecido em percentagem da estimativa da média. Para os demais caracteres, foi verificado um predomínio de variâncias homogêneas dentro de cultivares para caracteres mensurados na colheita e após o armazenamento refrigerado e variâncias heterogêneas entre cultivares. Com exceção da produção de etileno, todos os demais caracteres tiveram maiores variâncias para caracteres mensurados na cultivar 'Fuji', sugerindo a necessidade de utilização de tamanho de amostra (número de frutos) maior para a mensuração de caracteres nessa cultivar em relação à 'Royal Gala', na colheita e após o armazenamento refrigerado.

Para maçãs Royal Gala, o coeficiente de variação $(\mathrm{CV})$ oscilou entre 5,89 e $17,49 \%$ para os caracteres mensurados na colheita e de 3,98 a $23,66 \%$ para os caracteres mensurados após o armazenamento refrigerado (Tabela 1). Em maçãs Fuji, o coeficiente de variação na colheita variou entre 8,12 e $25,54 \%$ e de 3,41 a $34,74 \%$ após o armazenamento refrigerado. Com exceção do teor de suco, todos os demais caracteres mensurados apresentaram maior $\mathrm{CV}$ na cultivar 'Fuji' em relação à 'Royal Gala', reforçando as inferências supracitadas de que maior tamanho de amostra é necessário para a mensuração de frutos de maçãs Fuji.

De modo geral, os caracteres mensurados tanto na colheita como após o armazenamento refrigerado apresentaram assimetria não diferente de zero $(\mathrm{P}>0,05)$ nas duas cultivares (Tabela 2$)$. Além disso, todos os caracteres apresentaram curtose não diferente de três $(\mathrm{P}>0,05)$ e valor-p do teste de normalidade maior que 0,05 , indicando bom ajuste dos dados à distribuição normal. Assim, pode-se inferir que os dados são adequados para a estimação do tamanho de amostra com base na distribuição t de Student.

Entre os caracteres de maçãs Royal Gala e Fuji, avaliados na colheita e após o armazenamento refrigerado, maior tamanho de amostra (número de frutos) é necessário para a mensuração de: produção de etileno, ratio, respiração, massa e acidez titulável (Tabela 3). Menor tamanho de amostra é necessário para a mensuração do diâmetro longitudinal, da firmeza de polpa, dos sólidos solúveis totais, dos diâmetros transversais (maior e menor) e do teor de suco. Em pêssego Eldorado, TOEBE et al. (2012) verificaram que maiores tamanhos de amostra foram necessários para a estimação da média de firmeza de polpa, seguidos da massa, ratio e acidez e menores tamanhos de amostra foram necessários para a estimação da média do teor de suco, comprimento (diâmetro longitudinal), diâmetros transversais (maior e menor), coloração e sólidos solúveis totais.

Verificou-se similaridade do tamanho de amostra para caracteres mensurados na mesma cultivar, na colheita e após o armazenamento refrigerado, com exceção dos caracteres acidez titulável e ratio, que necessitam de maiores tamanhos de amostra após o armazenamento refrigerado (Tabela 3). Para todos os caracteres mensurados, com exceção do teor de suco, o tamanho de amostra necessário para a estimação da média em maçãs Royal Gala foi inferior ao tamanho de amostra necessário para maçãs Fuji. O tamanho de amostra (número de frutos) para a estimação da média de caracteres de maçãs Royal Gala, com erro de estimação de $1 \%$ da média, oscilou entre 137 e 1.200 frutos na colheita e entre 63 e 2.194 frutos após o armazenamento refrigerado. Já em maçãs Fuji, o tamanho de amostra oscilou entre 259 e 2.559 frutos na colheita e entre 46 e 4.739 frutos após o armazenamento refrigerado. Nesse mesmo nível de precisão, TOEBE et al. (2012) verificaram que, para a estimação da média de caracteres em pêssego Eldorado, é necessário mensurar de 31 a 1.954 frutos na colheita e de 33 a 4.213 frutos após o armazenamento refrigerado.

Em maçãs Royal Gala, 48 frutos são suficientes para a mensuração da massa, dos diâmetros longitudinal e transversais (maior e menor), da firmeza de polpa, dos sólidos solúveis totais, da acidez titulável e do ratio na colheita, com um erro de estimação de, no máximo, $5 \%$ da média (Tabela 3 ). O mesmo número de frutos é suficiente para a mensuração desses caracteres em frutos submetidos ao armazenamento refrigerado, sendo suficiente também para a mensuração 
Tabela 2 - Assimetria, Curtose +3 e valor-p do teste de normalidade de Kolmogorov-Smirnov para caracteres mensurados em quatro amostras, ou seja, na colheita (COL) e após o armazenamento refrigerado (AAR) em frutos de maçãs 'Royal Gala' e 'Fuji'.

\begin{tabular}{|c|c|c|c|c|c|}
\hline \multirow[b]{2}{*}{ Caractere } & \multirow[b]{2}{*}{ Unidade } & \multicolumn{2}{|c|}{-------------- 'Royal Gala' -------------- } & \multirow{2}{*}{\multicolumn{2}{|c|}{$\begin{array}{cc}\text { COL }(n=120) & \text { AAR }(n=111) \\
\operatorname{amostra} 3 & \text { amostra } 4\end{array}$}} \\
\hline & & $\begin{array}{c}\mathrm{COL}(\mathrm{n}=120) \\
\operatorname{amostra} 1\end{array}$ & $\begin{array}{c}\text { AAR }(n=120) \\
\text { amostra } 2\end{array}$ & & \\
\hline & \multicolumn{5}{|c|}{ 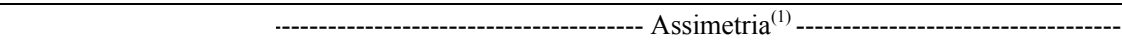 } \\
\hline Massa & G & $0,503 *$ & $0,280^{\mathrm{ns}}$ & $0,559^{*}$ & $0,674 *$ \\
\hline Diâmetro longitudinal & $\mathrm{Mm}$ & $0,504 *$ & $-0,127^{\mathrm{ns}}$ & $0,405^{\text {ns }}$ & $0,385^{\mathrm{ns}}$ \\
\hline Diâmetro transversal maior & $\mathrm{Mm}$ & $0,098^{\mathrm{ns}}$ & $0,123^{\mathrm{ns}}$ & $0,325^{\text {ns }}$ & $0,350^{\mathrm{ns}}$ \\
\hline Diâmetro transversal menor & $\mathrm{Mm}$ & $0,005^{\mathrm{ns}}$ & $0,138^{\mathrm{ns}}$ & $0,128^{\mathrm{ns}}$ & $0,363^{\mathrm{ns}}$ \\
\hline Firmeza de polpa & $\mathrm{N}$ & $-0,224^{\mathrm{ns}}$ & $0,063^{\mathrm{ns}}$ & $0,169^{\text {ns }}$ & $0,680 *$ \\
\hline Sólidos solúveis totais & ${ }^{\circ}$ Brix & $0,433 *$ & $-0,051^{\mathrm{ns}}$ & $-0,588^{*}$ & $-0,545^{*}$ \\
\hline Acidez titulável & \% ác. Málico & $0,547 *$ & $0,200^{\mathrm{ns}}$ & $0,969 *$ & $0,258^{\mathrm{ns}}$ \\
\hline Ratio & ${ }^{\circ}$ Brix $/ \%$ ác. málico & $0,448 *$ & $0,306^{\mathrm{ns}}$ & $-0,089^{\mathrm{ns}}$ & $0,429^{\mathrm{ns}}$ \\
\hline Teor de suco & $\%$ & - & $-0,317^{\mathrm{ns}}$ & - & $-0,168^{\mathrm{ns}}$ \\
\hline Etileno & $\mu \mathrm{L} \mathrm{C}_{2} \mathrm{H}_{4} \mathrm{~kg}^{-1} \mathrm{~h}^{-1}$ & - & $-0,406^{\mathrm{ns}}$ & - & $0,229^{\mathrm{ns}}$ \\
\hline Respiração & $\mathrm{mLCO}_{2} \mathrm{~kg}^{-1} \mathrm{~h}^{-1}$ & - & $0,431^{\mathrm{ns}}$ & - & $0,896^{*}$ \\
\hline & & & --- Curtos & $3^{(2)}-------$ & \\
\hline Massa & G & $3,167^{\mathrm{ns}}$ & $2,460^{\mathrm{ns}}$ & $2,751^{\mathrm{ns}}$ & $2,903^{\mathrm{ns}}$ \\
\hline Diâmetro longitudinal & $\mathrm{Mm}$ & $3,489^{\mathrm{ns}}$ & $2,419^{\mathrm{ns}}$ & $3,318^{\mathrm{ns}}$ & $3,062^{\mathrm{ns}}$ \\
\hline Diâmetro transversal maior & $\mathrm{Mm}$ & $2,701^{\mathrm{ns}}$ & $2,425^{\mathrm{ns}}$ & $2,461^{\mathrm{ns}}$ & $2,356^{\mathrm{ns}}$ \\
\hline Diâmetro transversal menor & $\mathrm{Mm}$ & $2,664^{\mathrm{ns}}$ & $2,337^{\mathrm{ns}}$ & $2,269^{\mathrm{ns}}$ & $2,335^{\mathrm{ns}}$ \\
\hline Firmeza de polpa & $\mathrm{N}$ & $2,849^{\mathrm{ns}}$ & $2,760^{\mathrm{ns}}$ & $3,301^{\mathrm{ns}}$ & $3,147^{\mathrm{ns}}$ \\
\hline Sólidos solúveis totais & ${ }^{\circ}$ Brix & $3,086^{\mathrm{ns}}$ & $2,770^{\mathrm{ns}}$ & $3,704^{\mathrm{ns}}$ & $3,502^{\mathrm{ns}}$ \\
\hline Acidez titulável & \% ác. Málico & $3,176^{\mathrm{ns}}$ & $2,267^{\mathrm{ns}}$ & $3,554^{\mathrm{ns}}$ & $2,351^{\mathrm{ns}}$ \\
\hline Ratio & ${ }^{\circ}$ Brix $/ \%$ ác. málico & $2,886^{\mathrm{ns}}$ & $2,477^{\mathrm{ns}}$ & $2,485^{\mathrm{ns}}$ & $2,516^{\mathrm{ns}}$ \\
\hline Teor de suco & $\%$ & - & $2,324^{\mathrm{ns}}$ & - & $2,283^{\mathrm{ns}}$ \\
\hline Etileno & $\mu \mathrm{L} \mathrm{C}_{2} \mathrm{H}_{4} \mathrm{~kg}^{-1} \mathrm{~h}^{-1}$ & - & $2,870^{\mathrm{ns}}$ & - & $2,663^{\mathrm{ns}}$ \\
\hline Respiração & $\mathrm{mL} \mathrm{CO}_{2} \mathrm{~kg}^{-1} \mathrm{~h}^{-1}$ & - & $2,861^{\mathrm{ns}}$ & - & $3,380^{\mathrm{ns}}$ \\
\hline Massa & G & 0,357 & 0,775 & 0,141 & 0,169 \\
\hline Diâmetro longitudinal & $\mathrm{Mm}$ & 0,218 & 0,444 & 0,180 & 0,671 \\
\hline Diâmetro transversal maior & $\mathrm{Mm}$ & 0,342 & 0,143 & 0,504 & 0,242 \\
\hline Diâmetro transversal menor & $\mathrm{Mm}$ & 0,600 & 0,190 & 0,324 & 0,055 \\
\hline Firmeza de polpa & $\mathrm{N}$ & 0,305 & 0,507 & 0,897 & 0,143 \\
\hline Sólidos solúveis totais & ${ }^{\circ}$ Brix & 0,235 & 0,464 & 0,130 & 0,192 \\
\hline Acidez titulável & \% ác. Málico & 0,354 & 0,262 & 0,072 & 0,506 \\
\hline Ratio & ${ }^{\circ} \mathrm{Brix} / \%$ ác. málico & 0,553 & 0,652 & 0,767 & 0,802 \\
\hline Teor de suco & $\%$ & - & 0,469 & - & 0,691 \\
\hline Etileno & $\mu \mathrm{L} \mathrm{C}_{2} \mathrm{H}_{4} \mathrm{~kg}^{-1} \mathrm{~h}^{-1}$ & - & 0,879 & - & 0,734 \\
\hline Respiração & $\mathrm{mLCO} \mathrm{Cg}^{-1} \mathrm{~h}^{-1}$ & - & 0,791 & - & 0,142 \\
\hline
\end{tabular}

(1) * Assimetria difere de zero, pelo teste t, em nível de $5 \%$ de probabilidade. ${ }^{\text {ns }}=$ Não-significativo. ${ }^{(2)} *$ Curtose difere de três, pelo teste t, em nível de $5 \%$ de probabilidade. ${ }^{\text {ns }}=$ Não-significativo

da respiração e do teor de suco. Apenas para a determinação da produção de etileno, é necessário usar um maior número de frutos ( 88 frutos) para obter a estimativa da média com essa mesma precisão. Nessa mesma cultivar e com mesmo nível de precisão, TOEBE et al. (2011) constataram a necessidade de mensuração de 24 frutos para a estimação da média de firmeza de polpa e cor de fundo da epiderme em frutos submetidos a diferentes tratamentos durante o armazenamento refrigerado. Em maçãs Fuji, 19 frutos são suficientes para a estimação da média dos diâmetros longitudinal e transversais (maior e menor), da firmeza de polpa, dos sólidos solúveis totais e do teor de suco, com um erro de estimação de, no máximo, $5 \%$ da média, tanto na colheita como após o armazenamento refrigerado. Para a estimação 
Tabela 3 - Tamanho de amostra (número de frutos) para a estimação da média de caracteres de frutos de maçãs 'Royal Gala' e 'Fuji', para erros de estimação iguais a $1,2, \ldots, 10 \%$ da estimativa da média e a semiamplitude do intervalo de confiança (Erro).

\begin{tabular}{|c|c|c|c|c|c|c|c|c|c|c|c|}
\hline Caractere & $1 \%$ & $2 \%$ & $3 \%$ & $4 \%$ & $5 \%$ & $6 \%$ & $7 \%$ & $8 \%$ & $9 \%$ & $10 \%$ & Erro $^{(1)}$ \\
\hline \multicolumn{12}{|c|}{--- } \\
\hline Massa & 1.200 & 300 & 134 & 75 & 48 & 34 & 25 & 19 & 15 & 12 & 3,16 \\
\hline Diâmetro longitudinal & 262 & 66 & 30 & 17 & 11 & 8 & 6 & 5 & 4 & 3 & 1,48 \\
\hline Diâmetro transversal maior & 161 & 41 & 18 & 11 & 7 & 5 & 4 & 3 & 2 & 2 & 1,16 \\
\hline Diâmetro transversal menor & 138 & 35 & 16 & 9 & 6 & 4 & 3 & 3 & 2 & 2 & 1,07 \\
\hline Firmeza de polpa & 263 & 66 & 30 & 17 & 11 & 8 & 6 & 5 & 4 & 3 & 1,48 \\
\hline Sólidos solúveis totais & 137 & 35 & 16 & 9 & 6 & 4 & 3 & 3 & 2 & 2 & 1,06 \\
\hline Acidez titulável & 437 & 110 & 49 & 28 & 18 & 13 & 9 & 7 & 6 & 5 & 1,91 \\
\hline Ratio & 531 & 133 & 59 & 34 & 22 & 15 & 11 & 9 & 7 & 6 & 2,10 \\
\hline \multicolumn{12}{|c|}{---Caracteres mensurados em frutos de maçãs 'Royal Gala' após o armazenamento refrigerado--- } \\
\hline Massa & 1.026 & 257 & 114 & 65 & 42 & 29 & 21 & 17 & 13 & 11 & 2,92 \\
\hline Diâmetro longitudinal & 232 & 58 & 26 & 15 & 10 & 7 & 5 & 4 & 3 & 3 & 1,39 \\
\hline Diâmetro transversal maior & 127 & 32 & 15 & 8 & 6 & 4 & 3 & 2 & 2 & 2 & 1,03 \\
\hline Diâmetro transversal menor & 119 & 30 & 14 & 8 & 5 & 4 & 3 & 2 & 2 & 2 & 0,99 \\
\hline Firmeza de polpa & 292 & 73 & 33 & 19 & 12 & 9 & 6 & 5 & 4 & 3 & 1,56 \\
\hline Sólidos solúveis totais & 122 & 31 & 14 & 8 & 5 & 4 & 3 & 2 & 2 & 2 & 1,01 \\
\hline Acidez titulável & 790 & 198 & 88 & 50 & 32 & 22 & 17 & 13 & 10 & 8 & 2,56 \\
\hline Ratio & 865 & 217 & 97 & 55 & 35 & 25 & 18 & 14 & 11 & 9 & 2,68 \\
\hline Teor de suco & 63 & 16 & 7 & 4 & 3 & 2 & 2 & 1 & 1 & 1 & 0,72 \\
\hline Etileno & 2.194 & 549 & 244 & 138 & 88 & 61 & 45 & 35 & 28 & 22 & 4,28 \\
\hline Respiração & 859 & 215 & 96 & 54 & 35 & 24 & 18 & 14 & 11 & 9 & 2,68 \\
\hline \multicolumn{12}{|c|}{ 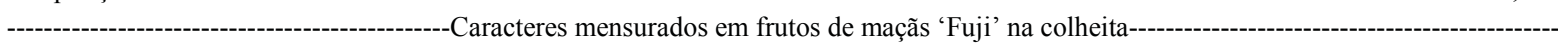 } \\
\hline Massa & 2.559 & 640 & 285 & 160 & 103 & 72 & 53 & 40 & 32 & 26 & 4,62 \\
\hline Diâmetro longitudinal & 462 & 116 & 52 & 29 & 19 & 13 & 10 & 8 & 6 & 5 & 1,96 \\
\hline Diâmetro transversal maior & 321 & 81 & 36 & 21 & 13 & 9 & 7 & 6 & 4 & 4 & 1,63 \\
\hline Diâmetro transversal menor & 259 & 65 & 29 & 17 & 11 & 8 & 6 & 5 & 4 & 3 & 1,47 \\
\hline Firmeza de polpa & 312 & 78 & 35 & 20 & 13 & 9 & 7 & 5 & 4 & 4 & 1,61 \\
\hline Sólidos solúveis totais & 445 & 112 & 50 & 28 & 18 & 13 & 10 & 7 & 6 & 5 & 1,92 \\
\hline Acidez titulável & 723 & 181 & 81 & 46 & 29 & 21 & 15 & 12 & 9 & 8 & 2,45 \\
\hline Ratio & 793 & 199 & 89 & 50 & 32 & 23 & 17 & 13 & 10 & 8 & 2,57 \\
\hline \multicolumn{12}{|c|}{ - } \\
\hline $\begin{array}{l}\text { Massa } \\
\text { Diâmetro lonoitudinal }\end{array}$ & 2.202 & 551 & 245 & 138 & 89 & 62 & 45 & 35 & $\begin{array}{l}28 \\
5\end{array}$ & 23 & $\begin{array}{r}4,45 \\
1,89\end{array}$ \\
\hline Diâmetro longitudinal & 399 & 100 & 45 & 25 & 16 & 12 & 9 & 7 & 5 & 4 & 1,89 \\
\hline Diâmetro transversal maior & 267 & 67 & 30 & 17 & 11 & 8 & 6 & 5 & 4 & 3 & 1,55 \\
\hline Diâmetro transversal menor & 241 & 61 & 27 & 16 & 10 & 7 & 5 & 4 & 3 & 3 & 1,47 \\
\hline Firmeza de polpa & 335 & 84 & 38 & 21 & 14 & 10 & 7 & 6 & 5 & 4 & 1,74 \\
\hline Sólidos solúveis totais & 457 & 115 & 51 & 29 & 19 & 13 & 10 & 8 & 6 & 5 & 2,03 \\
\hline Acidez titulável & 2.341 & 586 & 261 & 147 & 94 & 66 & 48 & 37 & 29 & 24 & 4,59 \\
\hline Ratio & 3.187 & 797 & 355 & 200 & 128 & 89 & 66 & 50 & 40 & 32 & 5,36 \\
\hline Teor de suco & 46 & 12 & 6 & 3 & 2 & 2 & 1 & 1 & 1 & 1 & 0,64 \\
\hline Etileno & 4.739 & 1.185 & 527 & 297 & 190 & 132 & 97 & 75 & 59 & 48 & 6,53 \\
\hline Respiração & 2.742 & 686 & 305 & 172 & 110 & 77 & 56 & 43 & 34 & 28 & 4,97 \\
\hline
\end{tabular}

${ }^{(1)}$ Erro (em \%) calculado com base em 120 frutos para maçãs 'Royal Gala' avaliadas na colheita e após o armazenamento refrigerado e, para maçãs 'Fuji', avaliadas na colheita e com base em 111 frutos para maçãs 'Fuji', avaliadas após o armazenamento refrigerado.

da média da massa, da acidez titulável, do ratio e da respiração nesse nível de precisão, recomenda-se a mensuração de 128 frutos e, para a estimação da produção de etileno, 190 frutos.

Em laranjas Valencia late, AVANZA et al. (2010) recomendaram a mensuração de 30 frutos por planta em sete plantas, totalizando 210 frutos, para a determinação do padrão de crescimento e do diâmetro dos frutos, com erro de estimação de 2 a $3 \%$ da média. Em laranja Valencia, BARRY et al. (1999) recomendaram a mensuração de quatro frutos por planta em 20 plantas, totalizando 80 frutos, para a 
determinação do teor de suco, sólidos solúveis totais, acidez e ratio. Na colheita e após o armazenamento a $22^{\circ} \mathrm{C}$ e $90 \%$ de UR, COELHO et al. (2011) verificaram que são necessários de um até 1.138 frutos para a estimação confiável (erro de estimação de 10\%) de características físicas e químicas do maracujáamarelo. Nesse caso, a variabilidade verificada no tamanho de amostra foi em função da característica mensurada, do estádio de maturação dos frutos na colheita e do momento de avaliação.

Com base na mensuração de 120 frutos de macieira Royal Gala na colheita e após o armazenamento refrigerado e com base em 120 e 111 frutos de macieira Fuji avaliadas na colheita e após o armazenamento refrigerado, respectivamente, em todos os caracteres avaliados, o erro de estimação foi inferior a 10\% (Tabela 3). Dessa forma, de modo geral, para maçãs Royal Gala e Fuji, a mensuração de 120 frutos garante a obtenção de médias precisas, cabendo ao pesquisador avaliar, dentro de sua disponibilidade de tempo, recursos financeiros e humanos, qual o dimensionamento de amostra adequado.

\section{CONCLUSÃO}

Entre os caracteres de maçã, maior tamanho de amostra é necessário para a estimação da média de: produção de etileno, ratio, respiração, massa e acidez titulável. Menor tamanho de amostra é necessário para a mensuração de: diâmetro longitudinal, firmeza de polpa, sólidos solúveis totais, diâmetros transversais (maior e menor) e teor de suco.

O tamanho de amostra para a mensuração de caracteres de maçãs na colheita e após o armazenamento refrigerado é similar. O tamanho de amostra necessário para a mensuração de caracteres de maçãs Royal Gala é menor em relação ao necessário para maçãs Fuji. Em maçãs Royal Gala e Fuji, 88 e 190 frutos, respectivamente, são suficientes para a mensuração de caracteres na colheita e após o armazenamento refrigerado, com erro de estimação de $5 \%$ da média.

\section{AGRADECIMENTOS}

Ao Conselho Nacional de Desenvolvimento Científico e Tecnológico (CNPq) pelas bolsas concedidas.

\section{REFERÊNCIAS}

AGRIANUAL. Anuário da Agricultura Brasileira. São Paulo: FNP, 2010. 520p.

AVANZA, M.M. et al. Tamaño óptimo de muestra para evaluar el patrón de crecimiento de frutos de naranjo 'Valencia Late'. Revista
Brasileira de Fruticultura, v.32, p.1154-1163, 2010. Disponível em: <http://www.scielo.br/pdf/rbf/v32n4/aop13810.pdf>. Acesso em: 15 fev. 2013. doi: 10.1590/S0100-29452010005000132.

BARRY, G.H. et al. Estimating optimal sample size for sweet orange fruit quality experiments. HortScience, v.34, p.483484, 1999. Disponível em: <http://hortsci.ashspublications.org/ content/34/3/483.5.abstract>. Acesso em: 15 fev. 2013.

BRACKMANN, A. et al. Indução da perda de massa fresca e a ocorrência de distúrbios fisiológicos em maçãs "Royal Gala" durante o armazenamento em atmosfera controlada. Revista Brasileira de Armazenamento, v.32, p.87-92, 2007.

BRACKMANN, A. et al. Manutenção da qualidade pós-colheita de maçãs 'Royal Gala' e 'Galaxy' sob armazenamento em atmosfera controlada. Ciência Rural, v.38, p. 2478-2484, 2008. Disponível em: <http://www.scielo.br/pdf/cr/v38n9/a10v38n9.pdf>. Acesso em: 02 set. 2013 . doi: 10.1590/S0103-84782008000900010.

BRACKMANN, A. et al. Temperatura, umidade relativa e atraso na instalação da atmosfera controlada no armazenamento de maçã 'Fuji'. Ciência Rural, v.39, p.2367-2372, 2009. Disponível em: $<$ http://www.scielo.br/pdf/cr/v39n8/a319cr1862.pdf $>$. Acesso em: 02 set. 2013. doi: 10.1590/S0103-84782009005000178.

BRACKMANN, A; SAQUET, A.A. Efeito das condições de atmosfera controlada sobre a ocorrência de degenerescência em maçãs 'Fuji'. Scientia Agricola, v.52, p.263-267, 1995. Disponível em: <http://www.scielo.br/pdf/sa/v52n2/10.pdf>. Acesso em: 15 fev. 2013. doi: 10.1590/S0103-90161995000200010.

BUSSAB, W.O.; MORETTIN, P.A. Estatística básica. 5.ed. São Paulo: Saraiva, 2004. 526p.

CHITARRA, M.I.F.; CHITARRA, A.B. Pós-colheita de frutas e hortaliças: fisiologia e manejo. 2.ed. Lavras: UFLA, 2005. 785p.

COELHO, A.A. et al. Dimensionamento amostral para a caracterização da qualidade póscolheita do maracujá-amarelo. Revista Ceres, v.58, p.23-28, 2011. Disponível em: <http://www. scielo.br/pdf/rceres/v58n1/a04v58n1.pdf>. Acesso em: 15 fev. 2013. doi: 10.1590/S0034-737X2011000100004.

CRUZ, C.D. Programa genes: estatística experimental e matrizes. Viçosa: UFV, 2006. 285p.

MIRANDA, C. et al. Random sample estimates of tree mean for fruit size and colour in apple. Scientia Horticulturae, v.112, p.3341, 2007. Disponível em: <http://www.sciencedirect.com/science/ article/pii/S0304423806004894>. Acesso em: 15 fev. 2013. doi: 10.1016/j.scienta.2006.12.006.

NAKANO, R. et al. Ethylene biosynthesis in detached young persimmon fruit is initiated in calyx and modulated by water loss from the fruit. Plant Physiology, v.131, p.276-286, 2003. Disponível em: <http://www.ncbi.nlm.nih.gov/pmc/articles/ PMC166807/>. Acesso em: 15 fev. 2013. doi: 10.1104/pp.010462.

SCHWARZ, A. Relative humidity in cool stores: measurement, control and influence of discreet factors. Acta Horticulturae, v.368, p.687-692, 1994. Disponível em: <http://www.actahort.org/ books/368/368_82.htm>. Acesso em: 15 fev. 2013.

SILVA, A.R. et al. Tamanho de amostra para caracterização morfológica de frutos de pimenteira. Horticultura Brasileira, 
v.29, p.125-129, 2011. Disponível em: <http://www.scielo.br/pdf/ $\mathrm{hb} / \mathrm{v} 29 \mathrm{n} 1 / 22$.pdf $>$. Acesso em: 15 fev. 2013. doi: 10.1590/S010205362011000100022 .

SPIEGEL, R.A. et al. Probabilidade e estatística. 2.ed. Porto Alegre: Bookman, 2004. 398p.

TOEBE, M. et al. Dimensionamento amostral para avaliar firmeza de polpa e cor da epiderme em pêssego e maçã. Revista Ciência
Agronômica, v.42, p.1026-1035, 2011. Disponível em: <http:// www.scielo.br/pdf/rca/v42n4/a27v42n4.pdf>. Acesso em: 15 fev. 2013. doi: S1806-66902011000400027.

TOEBE, M. et al. Tamanho de amostra para a estimação da média de caracteres de pêssego na colheita e após o armazenamento refrigerado. Ciência Rural, v.42, p.209-212,2012. Disponível em: $<$ http://www.scielo.br/pdf/cr/v42n2/a5912cr4891.pdf>. Acesso em: 15 fev. 2013. doi: 10.1590/S0103-84782012000200004. 